Research Article

\title{
Electrochemical Determination of Triclosan Using ZIF- 11/Activated Carbon Derived from the Rice Husk Modified Electrode
}

\author{
Nguyen Dinh Luyen, ${ }^{1}$ Tran Thanh Tam Toan, ${ }^{2}$ Ha Thuy Trang, ${ }^{1}$ Vo Thang Nguyen, ${ }^{3}$ \\ Le Van Thanh Son, ${ }^{3}$ Tran Si Thanh, ${ }^{4,5}$ Nguyen Mau Thanh, ${ }^{6}$ Phan Tu Quy, \\ and Dinh Quang Khieu (iD)
}

\author{
${ }^{1}$ University of Education, Hue University, 530000, Vietnam \\ ${ }^{2}$ Dong A University, 550000, Vietnam \\ ${ }^{3}$ University of Education and Science, The University of Da Nang, 55000, Vietnam \\ ${ }^{4}$ University of Sciences, Hue University, 530000, Vietnam \\ ${ }^{5}$ Department of Education and Training, Dak Nong Province 640000, Vietnam \\ ${ }^{6}$ Faculty of Natural Science, Quang Binh University, 510000, Vietnam \\ ${ }^{7}$ Faculty of Natural Science, Tay Nguyen University, 630000, Vietnam
}

Correspondence should be addressed to Dinh Quang Khieu; dqkhieu@hueuni.edu.vn

Received 24 April 2021; Revised 26 August 2021; Accepted 16 September 2021; Published 1 October 2021

Academic Editor: Duy Trinh Nguyen

Copyright (C) 2021 Nguyen Dinh Luyen et al. This is an open access article distributed under the Creative Commons Attribution License, which permits unrestricted use, distribution, and reproduction in any medium, provided the original work is properly cited.

\begin{abstract}
In the present paper, the composite of zeolite imidazolate framework-11 (ZIF-11) and activated carbon derived from rice husks (RHAC) was synthesized. The obtained materials were characterized by XRD, SEM, EDX-mapping, and nitrogen adsorption/desorption isotherms. The final composite ZIF-11/RHAC exhibits an even dispersion of ZIF-11 particles on activated carbon matrix. Herein, an electrochemical sensor based on a ZIF-11/RHAC was developed for a rapid determination of triclosan (TCS). It was found that the oxidation of TCS is irreversible and involves the transfer of one electron. The linear range for TCS detection in the optimized experimental conditions was found to be $0.1-8 \mu \mathrm{M}$ with the limit of detection of $0.076 \mu \mathrm{M}$. Finally, the proposed method was successfully employed to detect TCS in different personal care product samples with high accuracy, which was confirmed by a good agreement between these results and those obtained using highperformance liquid chromatography (HPLC).
\end{abstract}

\section{Introduction}

Triclosan (2,4,4' -trichloro-2' -hydroxydiphenyl ether) (denoted as TCS) with broad-spectrum antimicrobial activity against most gram-negative and gram-positive bacteria has been widely used for several decades. TCS can be found in formulations of various personal care products such as liquid toothpaste, cosmetics, antiseptic soaps, and shampoo. Due to its extensive use, there is a potential for human being in all age groups to be at risk of life-time exposures to TCS [1].
TCS is also highly toxic to aquatic animals $[2,3]$. It was found that the MicrotoxR bacterium, crustacean, and fish had similar sensitivities towards TCS toxicity (i.e., IC25 from 0.07 to $0.29 \mathrm{mg} / \mathrm{L}$ TCS). In contrast, the microalga was about 30 - to 80 -fold (IC25 $=0.0034 \mathrm{mg} / \mathrm{L}$ TCS) more sensitive to TCS toxicity. Due to these effects to both aquatic environment and human, several analytical techniques have been devoted for TCS detection in various types of samples, such as dispersive liquid-liquid microextraction combined with rapid liquid chromatography [4], liquid chromatography 
tandem mass spectrometry [2], spectrophotometry [5], electron capture negative ionization mass spectrometry [6], and electrochemistry [7].

Although these approaches are highly selective and sensitive and can be employed in different sample matrices, most of them are associated with several disadvantages, including time-consuming, complicated treatment of samples or high cost of equipment. In contrast, the electrochemical methods with numerous advantages offer a simple and sensitive quantitative approach with reduced cost and minimum sample volume required. Therefore, some electrochemical techniques, such as square wave voltammetry (SWV) or differential pulse voltammetry (DPV), were studied as interesting alternative detection methods. Recently, the development of porous materials with hierarchical structure has provided various sensors for TCS detection. Different electrodes such as ordered mesoporous carbon (CMK3) functionalized electrodes [8], graphene/palladium nanoparticle hybrids [9], $\beta$-cyclodextrin functionalized graphene nano platelets [10], and carbon nanodots/chitosan [11] have been developed providing sensitive, selective, and stable electrochemical sensors for the TCS detection. All of these manifest that porous materials play an important role on designing sensitive TCS sensors. Thus, the design of new nanomaterials for further accelerating the development of electroanalytical methods is highly desirable yet challenging.

Zeolite imidazolate frameworks (ZIFs) is a subclass of metal organic framework (MOF) compound with tetrahedral coordination of transition-metal $\left(\mathrm{Zn}^{2+}, \mathrm{Co}^{2+} \ldots\right)$ and imidazole ions to form zeolite-like 3D networks. They exhibit exceptional chemical stability even under refluxing condition with organic solvents, water, and alkaline aqueous solution [12]. Among ZIFs, ZIF-11 (large cages size of $14.6 \AA$ and small windows of $3.0 \AA$ ) with rhombic dodecahedron (RHO) topology formed from $\mathrm{Zn}^{2+}$ cation and benzimidazolate linker are relevant for the encapsulation of molecules of a certain size range to provide a composite material. ZIF-11 is one of the most auspicious ZIFs for gas separation and $\mathrm{H}_{2}$ adsorption [13]. Its application in matrix membranes has also been developed [14].

Activated carbon (AC) is widely used as a material for supercapacitor electrode, thanks to its low cost, high specific surface area, and good conductivity $[15,16]$. AC is a carbonaceous material produced from a wide variety of carbonrich raw materials such as coconut shells, rice husks, wood, and coal. Rice husk (>37\% carbon element by weight [17]) is an agricultural waste which is found abundantly in riceproducing countries, thus making it a potential raw material for producing AC. The preparation of rice husk-derived AC material with high carbon content ( $>90 \%$ carbon content) and surface area $\left(>2000 \mathrm{~m}^{2} / \mathrm{g}\right)$ obtained from the removal of silica via alkali leaching at room temperature (ca. $30^{\circ} \mathrm{C}$ ) was reported [18]. Although ZIF-11 possesses several advantages such as large surface area, uniform porous system, and abundant activate sites, the poor conductivity limits its application in electrochemical field. Therefore, the combination of ZIF-11 with RHAC is expected to form the potential materials for electrochemical application. According to the best knowledge, few articles have been reported on the
ZIF-11/RHAC composite as an electrode modifier for the detection of TCS by voltammetry method.

In the present article, the composites of ZIF-11 and RHAC were synthesized. The electrochemical behavior of electrode modified by ZIF-11/RHAC was studied by cyclic and differential pulse voltammetry. The analytical performance of TCS in some cosmetic products was conducted.

\section{Experimental}

2.1. Materials. Rice husks were collected from a rice mill in local area (TT-Hue province, Vietnam). The sample was stored in desiccator for further use. Zinc acetate dihydrate $\left(\mathrm{Zn}\left(\mathrm{CH}_{3} \mathrm{COOH}\right)_{2} \cdot 2 \mathrm{H}_{2} \mathrm{O}\right.$, 98\%), benzimidazole $\left(\mathrm{C}_{7} \mathrm{H}_{6} \mathrm{~N}_{2}\right.$, 99\%), methanol $\left(\mathrm{CH}_{3} \mathrm{COH}, 99.8 \%\right)$, absolute ethanol $\left(\mathrm{C}_{2} \mathrm{H}_{5}-\mathrm{OH}, 99.5 \%\right)$, toluene $\left(\mathrm{C}_{6} \mathrm{H}_{5}-\mathrm{CH}_{3}, 99.5 \%\right)$, ammonium hydroxide solution $\left(28 \% \mathrm{NH}_{3}\right.$ in $\left.\mathrm{H}_{2} \mathrm{O}\right)$, sodium hydroxide pellets $(\mathrm{NaOH}, 99 \%)$, and TCS $\left(\mathrm{C}_{12} \mathrm{H}_{7} \mathrm{Cl}_{3} \mathrm{O}_{2}, 97 \%\right)$ were received from Merck (Germany). Other chemicals were of analytical grade and used as received. The stock solution of TCS $(2.0 \mathrm{mM})$ was prepared with ethanol and stored in a refrigerator at $4^{\circ} \mathrm{C}$.

2.2. Synthesis of RHAC. The experimental procedure was conducted according to literature [19]. Typically, $20 \mathrm{~g}$ of minced rice husk (RH) was immersed in $1000 \mathrm{~mL}$ of $1 \mathrm{M}$ $\mathrm{NaOH}$ solution for $24 \mathrm{~h}$ at ambient condition before being filtered and dried at $100^{\circ} \mathrm{C}$ for $24 \mathrm{~h}$ to remove the silica. The obtained $\mathrm{RH}$ was carbonized at $400^{\circ} \mathrm{C}$ for $4 \mathrm{~h}$ to yield the charcoal product which was further treated with $60 \mathrm{~mL}$ of $1 \mathrm{M} \mathrm{NaOH}$ solution at room temperature for $20 \mathrm{~min}$ to completely remove any traces of silica. This solid was then washed with distilled water, filtered, and dried at $100^{\circ} \mathrm{C}$ for 24 hours. The pure charcoal was activated to form the activated carbon (RHAC) by mixing with a required amount of $\mathrm{KOH}$ and distilled water $\left(\mathrm{KOH}\right.$ : charcoal : $\mathrm{H}_{2} \mathrm{O}=1: 3$ : $5(\mathrm{~g} / \mathrm{g} / \mathrm{g}))$ under sonication condition for $15 \mathrm{~min}$. The mixture was dried at $100^{\circ} \mathrm{C}$ overnight and subsequently activated at $750^{\circ} \mathrm{C}$ for $1 \mathrm{~h}$ under nitrogen atmosphere to obtain RHAC. The RHAC samples were then washed with copious amount of distilled water until $\mathrm{pH} 7$ and stored for further study.

2.3. Synthesis of ZIF-11. The preparation of ZIF-11 was conducted according to literature [20]. In a typical process, $3.6 \mathrm{~g}$ of benzimidazole was dissolved in $183 \mathrm{~mL}$ of methanol. Then, $160 \mathrm{~mL}$ of toluene and $7 \mathrm{~mL}$ of ammonium hydroxide were poured into the benzimidazole/methanol solution under stirring condition at room temperature, followed by the addition of $3.3 \mathrm{~g}$ of zinc acetate dihydrate. The obtained mixture was stirred for $3 \mathrm{~h}$ at room temperature to obtain white powder which was then collected by centrifugation and washed five times with methanol ( $10 \mathrm{~mL}$ each) and dried at ambient temperature in air. The resulting white powder is ZIF-11.

2.4. Synthesis of ZIF-11/RHAC. Firstly, a mixture of benzimidazole, methanol, toluene, ammonium hydroxide, and RHAC was stirred for $50 \mathrm{~min}$ at room temperature, followed by the addition of zinc acetate dihydrate (the composition of 
TABLE 1: The mass and volume of chemicals used in the synthesis of ZIF-11/RHAC composite.

\begin{tabular}{lcccc}
\hline RHAC $(\mathrm{g})$ & 1 & 1 & 1 & 1 \\
Benzimidazole $(\mathrm{g})$ & 0.400 & 0.800 & 1.200 & 1.600 \\
Zinc acetate $(\mathrm{g})$ & 0.370 & 0.740 & 1.110 & 1.480 \\
Methanol $(\mathrm{mL})$ & 20 & 40 & 60 & 120 \\
Toluene $(\mathrm{mL})$ & 18 & 36 & 54 & 72 \\
Ammonia $(\mathrm{mL})$ & 0.8 & 1.6 & 2.4 & 3.2 \\
The dried mass $(\mathrm{g})$ & 1.361 & 1.477 & 1.720 & 2.030 \\
Notation & $(0.36 / 1)$ ZIF-11/RHAC & $(0.48 / 1)$ ZIF-11/RHAC & $(0.72 / 1)$ ZIF-11/RHAC & $(1.03 / 1)$ ZIF-11/RHAC \\
\hline
\end{tabular}

each mixture as Table 1). The obtained mixture was further mixed under ultrasonic irradiation for another $3 \mathrm{~h}$ at room temperature to finally form a black powder which was then collected by centrifugation and washed five times with methanol $(10 \mathrm{~mL}$ each), and dried at ambient temperature in air to obtain ZIF-11/RHAC material. The mass of ZIF-11 in the composite was calculated as the difference between the mass of the dried product and the mass of RHAC. The above synthesis procedure has resulted in ZIF-11/RHAC materials with different mass ratios denoted as (0.36/1) ZIF11/RHAC, (0.48/1) ZIF-11/RHAC, (0.72/1) ZIF-11/RHAC, and (1.03/1) ZIF-11/RHAC in which the fraction in parenthesis presents mass ratio of ZIF-11/mass of RHAC. A summary of reagents in the synthesis of different ZIF-11/RHAC composites is presented in Table 1.

The drift $\mathrm{pH}$ method was performed according to reference [21]. Briefly, to each of $200 \mathrm{~mL}$ flask, $0.01 \mathrm{~g}$ of $(0.62 / 1)$ ZIF-11/RHAC and $20 \mathrm{~mL} 0.01 \mathrm{M} \mathrm{NaCl}$ solution were added. Subsequently, a known amount of standardized $0.1 \mathrm{M} \mathrm{HCl}$ or $0.1 \mathrm{M} \mathrm{KOH}$ was added to obtain a specific $\mathrm{pH}$ in a range of 2-12. The flasks were then filled with double-distilled water to a total volume of $50 \mathrm{~mL}$ ( $\mathrm{pH}$ recorded and denoted as $\mathrm{pHi}$ ). They were then shaken with cap on for 24 hours at $25^{\circ} \mathrm{C}$. The final $\mathrm{pH}$ values (denoted as $\mathrm{pH}_{\mathrm{f}}$ ) of the supernatant in each flask was measured. The point of zero charge $\left(\mathrm{pH}_{\mathrm{PZC}}\right)$ was obtained from the plot of the $\Delta \mathrm{pH}(\Delta \mathrm{pH}=$ $\mathrm{pH}_{\mathrm{f}}-\mathrm{pH}_{\mathrm{i}}$ ) against $\mathrm{pHi}$ at $\Delta \mathrm{pH}=0$.

2.5. Instruments. Electrochemical experiments were performed by using an electrochemical analyzer (CPA, Vietnam), with a three-electrode cell including a glassy carbon electrode working electrode $(\varnothing=3 \mathrm{~mm})$, a $\mathrm{Ag} / \mathrm{AgCl} / 3 \mathrm{M}$ $\mathrm{KCl}$ reference electrode, and a platinum wire auxiliary electrode. The distance between the working electrode and reference electrode is $10 \mathrm{~mm}$. Cyclic voltammetry experiments was performed over a potential range of -0.2 to $1.2 \mathrm{~V}$ at a scan rate of $0.1 \mathrm{Vs}^{-1}$. Different pulse anodic voltammetry (DPV) was also conducted over a potential range of -0.2 to $1.2 \mathrm{~V}$ at a scan rate of $0.0625 \mathrm{Vs}^{-1}$ with pulse attitude of $0.07 \mathrm{~V}$, accumulation potential of $-0.8 \mathrm{~V}$, and accumulation time of $25 \mathrm{~s}$. The modified electrode was subjected to around $10 \mathrm{CV}$ scans in the Britton-Robinson buffer solution (denoted as BRS buffer) to obtain the stable CV before electrochemical experiments were performed.

The structural characteristics of the material was obtained from X-ray diffraction (XRD) measurements in a JED-2300 JEOL. Scanning electron microscopy (SEM) observation was performed on a SEM-JEOL-JSM $5410 \mathrm{LV}$, equipped with an Energy Dispersive Spectrometer (EDS) mapping analyzer, 7593-H (HORIBA, Japan). The powder was dispersed in carbon tape of EDS analysis. Textural properties were examined by nitrogen adsorption-desorption isotherms using a Micromeritics Tristar 3000, where the samples were previously degassed at $120^{\circ} \mathrm{C}$ for $12 \mathrm{~h}$. The total specific surface area was calculated based on Brunauer-Emmett-Teller (BET) model using the relative pressure range of $0.01-0.25 \mathrm{p} / \mathrm{p}_{\mathrm{o}}$. The micropore and mesopore surface areas were calculated by $t$-plot method. A Tomy Ultrasonic Disruptor (UD-200) was employed for the ultrasound source $(20 \mathrm{kHz})$. The HPLC (Thermo Scientific UltiMate 3000 UPLC) was used to determine TCS concentration for the sake of comparison. The chromatographic conditions were as follows: UV detector $(\lambda=280 \mathrm{~nm})$, flow rate of $0.5 \mathrm{~mL} \cdot \mathrm{min}^{-1}$ with the injection volume of $10 \mu \mathrm{L}$, and column temperature of $30^{\circ} \mathrm{C}$. The quantitative analysis was performed with external standardisation by measuring the peak areas on the chromatograms.

2.6. The Electrode Modification and Samples Pretreatment. The modified electrode was prepared by drop-casting a certain amount of ZIF-11/RHAC suspension onto a clean glassy carbon electrode (GCE). Prior to the modification with ZIF-11/RHAC, the GCE was cleaned with $0.3 \mathrm{~mm}$ alumina powder, ultrasonically cleaned in ethanol and water, and dried in air. ZIF-11/RHAC suspension was obtained by dispersing $1 \mathrm{mg}$ of ZIF-11/RHAC in $1 \mathrm{~mL}$ of distilled water with the aid of ultrasonic stirring for $45 \mathrm{~min}$. ZIF$11 /$ RHAC suspension was kept at $4^{\circ} \mathrm{C}$ for further use. Finally, $5 \mu \mathrm{L}$ of the ZIF-11/RHAC suspension were dropped on the cleaned GCE, and the solvent was allowed to evaporate at ambient condition. The modified GCE was denoted as ZIF-11/RHAC/GCE. The modification of GCE was also performed by ZIF-11 and RHAC denoted as ZIF-11/GCE and RHAC/GCE, respectively, for comparison.

Solution containing TCS extracted from cosmetic samples was prepared by dispersing about $0.5 \mathrm{~g}$ sample to $10 \mathrm{~mL}$ of $70 \%$ ethanol $(v / v)$ in ultrasonication condition. After that, the filtrate was collected by filtering through $0.45 \mu \mathrm{m} \mathrm{mem-}$ brane, then diluted to $10.0 \mathrm{~mL}$ for further detection.

\section{Results and Discussion}

3.1. Synthesis of ZIF-11/Activated Carbon Derived from Rice Husk (ZIF-11/RHAC). Figure 1(a) presents XRD patterns of 


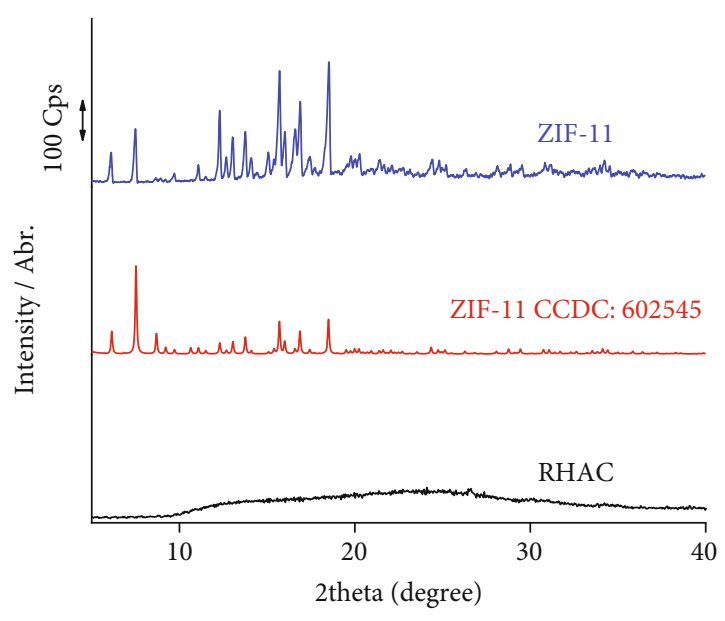

(a)

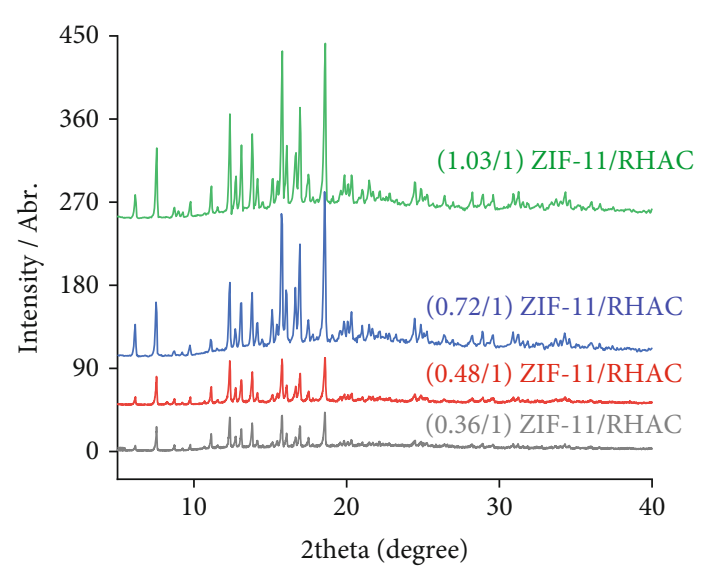

(b)

Figure 1: XRD patterns of (a) RHAC and ZIF-11 and (b) ZIF-11/RHAC.

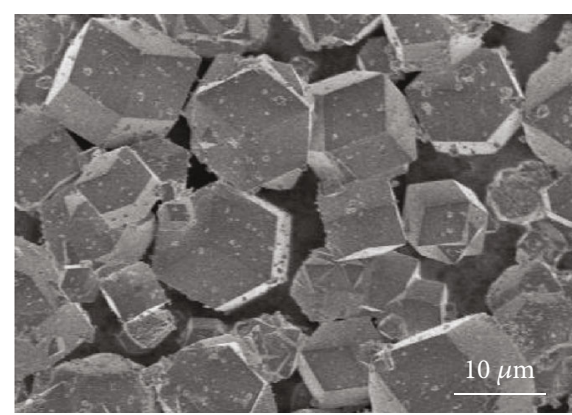

(a)

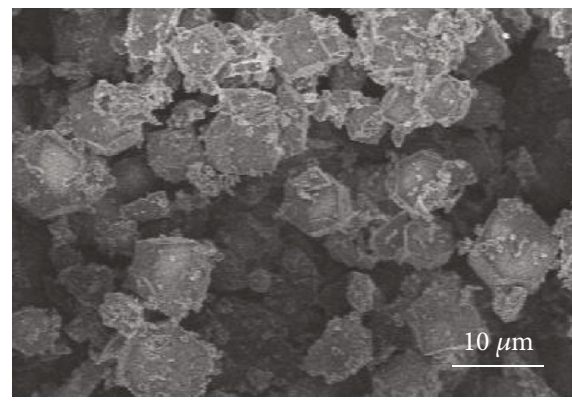

(c)

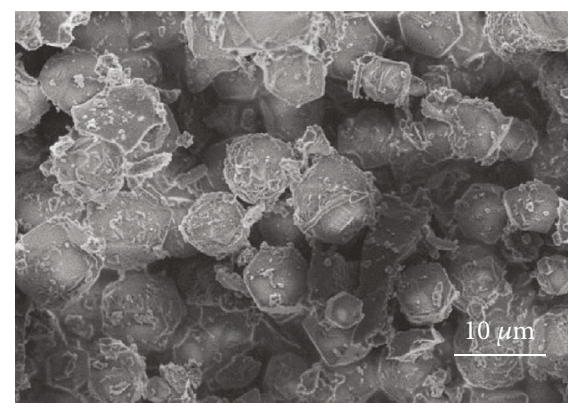

(e)

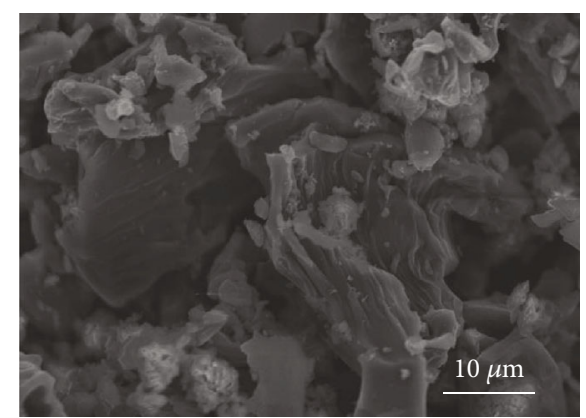

(b)

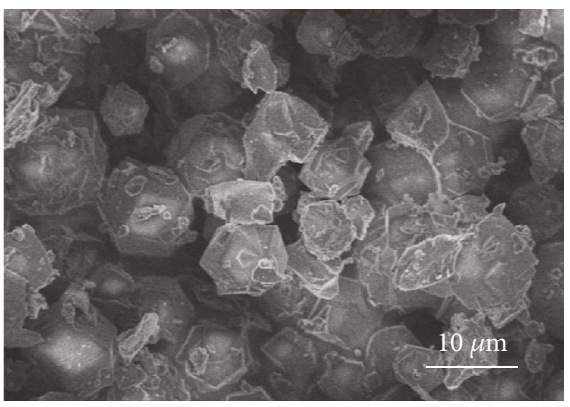

(d)

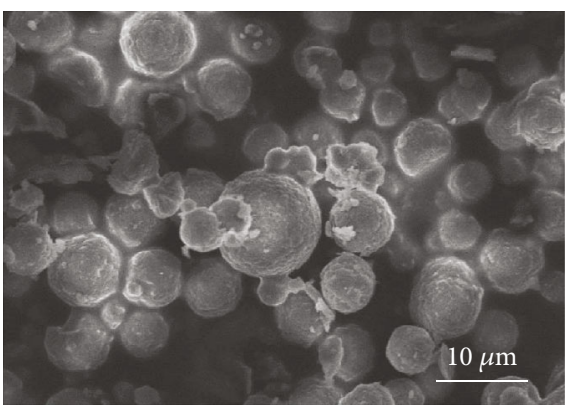

(f)

Figure 2: SEM images of (a) ZIF-11, (b) RHAC, (c) (0.36/1) ZIF-11/RHAC, (d) (0.48/1) ZIF-11/RHAC, (e) (0.72/1) ZIF-11/RHAC, and (f) (1.03/1) ZIF-11/RHAC. 


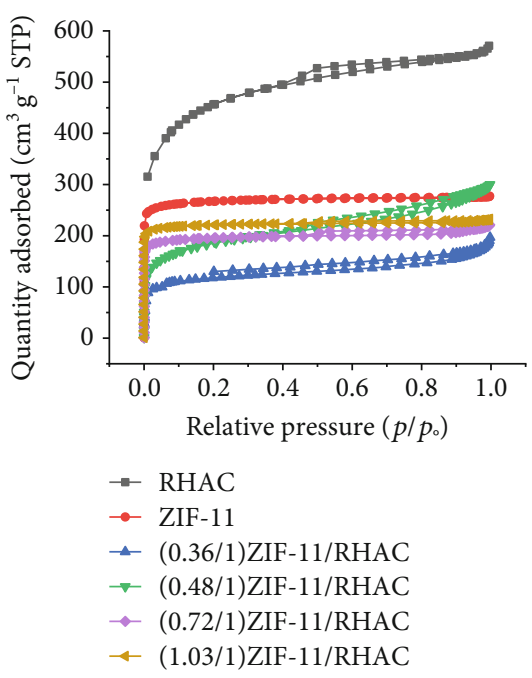

(a)

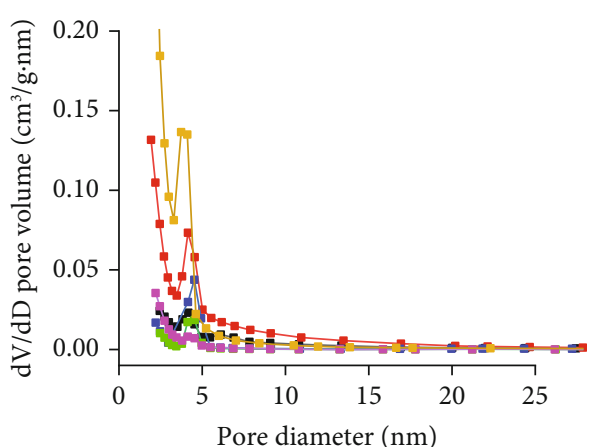

- $(0.36 / 1)$ ZIF-11/RHAC

$\rightarrow(0.48 / 1)$ ZIF-11/RHAC

$\rightarrow(0.72 / 1) \mathrm{ZIF}-11 /$ RHAC

$-(1.03 / 1)$ ZIF-11/RHAC

- ZIF-11

$\because$ RHAC

FIGURE 3: (a) Nitrogen adsorption/desorption isotherms and (b) pore size distribution curves of RHAC, ZIF-11, and ZIF-11/RHAC.

TABLE 2: The specific surface areas of the ZIF-11, RHAC, and ZIF-11/RHAC composites.

\begin{tabular}{lcccc}
\hline Materials & $S_{\text {BET }}\left(\mathrm{m}^{2} \cdot \mathrm{g}^{-1}\right)$ & $S_{\text {Micropore }}\left(\mathrm{m}^{2} \cdot \mathrm{g}^{-1}\right)$ & $S_{\text {Mesopore }}\left(\mathrm{m}^{2} \cdot \mathrm{g}^{-1}\right)$ & $V_{\text {total pore }}\left(\mathrm{cm}^{3} \cdot \mathrm{g}^{-1}\right)$ \\
\hline ZIF-11 & 1067 & 1044 & 23 & 785 \\
RHAC & 1500 & 715 & 96 & 571 \\
$(0.36 / 1)$ ZIF-11/RHAC & 443 & 347 & 241 & 197 \\
$(0.48 / 1)$ ZIF-11/RHAC & 664 & 423 & 34 & 300 \\
$(0.72 / 1)$ ZIF-11/RHAC & 776 & 742 & 22 & 221 \\
$(1.03 / 1)$ ZIF-11/RHAC & 897 & 875 & & 233 \\
\hline
\end{tabular}

the activated carbon derived from rice husk (RHAC), ZIF11, and the ZIF-11/RHAC composites. XRD pattern with high background and no diffraction is observed for RHAC indicating that RHAC exists in the amorphous form. ZIF11 sample exhibits its characteristic diffractions which were indexed according to Cambridge Crystallographic Data Centre (CCDC) by citing deposition numbers 602545. The high and sharp peaks indicate excellent crystallinity and RHO topology of ZIF-11. The XRD patterns of ZIF-11/RHAC composites exhibit all X-ray diffractions of ZIF-11 but the magnitude of diffractions increases with the increase of ZIF-11 content due to increasing contribution of crystalline fraction of ZIF-11 (Figure 1(b)).

The morphology of the obtained samples was observed by SEM images. Figure 2 presents representative SEM images of RHAC, ZIF-11, and ZIF-11/RHAC composites. The ZIF-11 displays highly crystalline faceted rhombohedra (Figure 2(a)). Meanwhile, the morphology of RHAC consists of irregular particles (Figure 2(b)) which could be attributed to the gasification of volatiles upon activation. The morphology of ZIF-11/RHAC composite is presented in (Figures 2(c)-2(f)). As seen from the figures, there is a transformation of particle morphology from rhombic dodecahedral to spherical with increasing amount of ZIF-11 in the

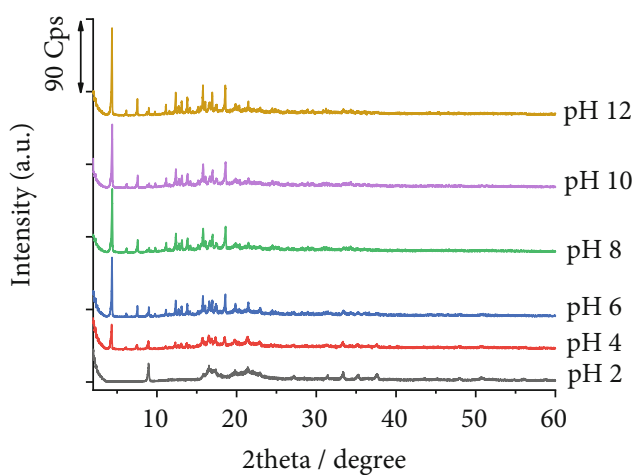

FIGURE 4: XRD patterns of (1.03/1) ZIF11/RHAC at different pH.

composite. As small amount of ZIF-11 was introduced to RHAC, an even dispersion of rhombic dodecahedron ZIF11 in RHAC matrix was observed in the samples of $(0.36 / 1)$ ZIF-11/RHAC and (0.48/1) ZIF-11/RHAC. However, as the proportion of ZIF-11 increases, RHAC particles tend to adsorb to the surface of ZIF-11 crystals, especially to the edge of crystals resulting in the transforming of rhombic dodecahedron to spherical shape as observed in the samples of $(0.72 / 1)$ ZIF-11/RHAC and (1.03/1) ZIF-11/RHAC. 


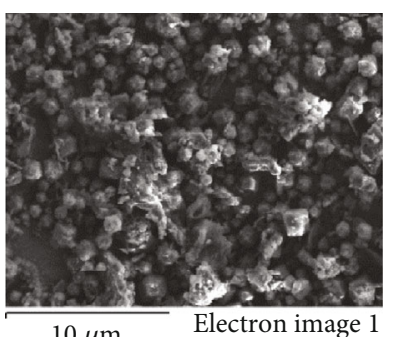

$10 \mu \mathrm{m}$

(a)

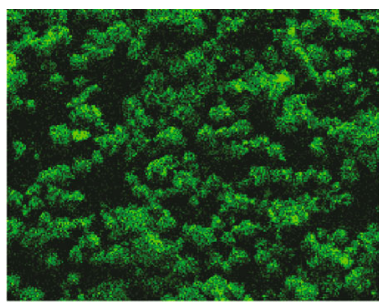

C Kal_2

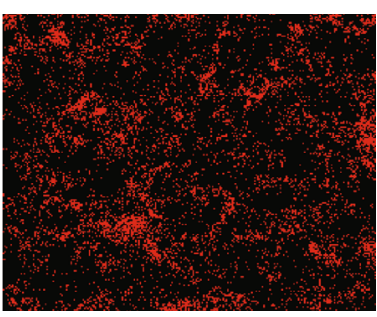

$\mathrm{O} \mathrm{Ka} 1$

(b)

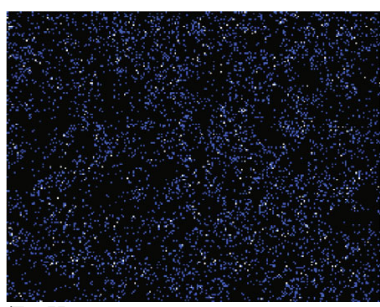

Zn Kal

(d)

(c)

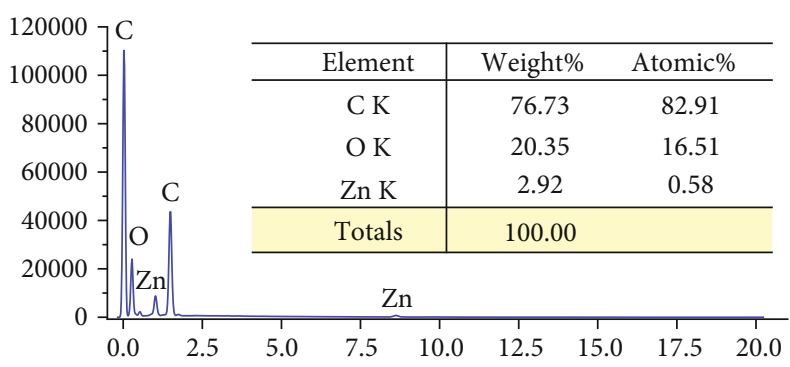

(e)

Figure 5: Elemental mapping of the (0.72/1) ZIF-11/RHAC: (a) bright field image, (b) mapping of oxygen, (c) mapping of carbon, (d) mapping of zinc, and (e) EDX spectrum of (1.03/1) ZIF-11/RHAC.

Figure 3(a) shows the nitrogen adsorption-desorption isotherms for the obtained samples. Type I isotherm characteristic indicates that ZIF-11 contains mainly micropores. In contrast, RHAC and the composite of ZIF-11/RHAC present type IV isotherms with H4-type distinct hysteresis loops between the adsorption/desorption branches at high relative pressures $\left(p / p_{0}=0.2-0.9\right)$ which are characteristic for meso/microporous materials $[22,23]$. The plot of pore size distribution of the ZIF-11 shows a broad peak while that of RHAC and ZIF-11/RHAC composites presents a sharp peak at diameters of around $4.2-4.5 \mathrm{~nm}$ which are assigned to mesopore system formed between particles or layers (Figure 3(b)). The BET surface areas extracted from these isotherms are $1500 \mathrm{~m}^{2} / \mathrm{g}$ for RHAC and $1067 \mathrm{~m}^{2} / \mathrm{g}$ for ZIF11 (Table 2). It is known that ZIF-11 is nonporous to nitrogen because its aperture size $(3.0 \AA)$ was smaller than the kinetic diameter of nitrogen $(3.6 \AA)$ [12, 24]. Therefore, the specific surface area of ZIF-11 based on nitrogen adsorption measurement is smaller than other ZIFs such as ZIF-8 or ZIF-12 [25]. The reported specific surface area of materials based on BET model also varies with various synthesis conditions, from $97 \mathrm{~m}^{2} \mathrm{~g}^{-1}$ (ethanol solvent, at room temperature) [25] to $350.29 \mathrm{~m}^{2} \mathrm{~g}^{-1}$ (methanol solvent, at room temperature) [26] and $745 \mathrm{~m}^{2} \mathrm{~g}^{-1}$ (microwave heating) [27].

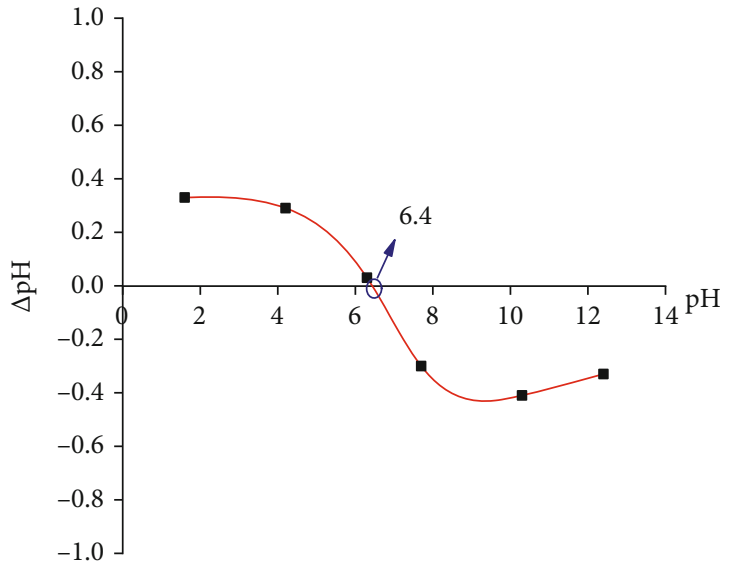

FIgURE 6: The point of zero charge of $(0.72 / 1)$ ZIF-11/RHAC.

The surface area of RHAC found at $1500 \mathrm{~m}^{2} \cdot \mathrm{g}^{-1}$ is comparable to the previous literature [28]. The surface area for the mixture of ZIF-11 and RHAC decreases significantly compared with individual components. The specific surface area of ZIF-11/RHAC composite is in the order of (1.03/1) ZIF-11/RHAC $\quad\left(897 \mathrm{~m}^{2} \cdot \mathrm{g}^{-1}\right)>(0.72 / 1) \quad$ ZIF-11/RHAC $\left(776 \mathrm{~m}^{2} \cdot \mathrm{g}^{-1}\right)>(0.48 / 1)$ ZIF-11/RHAC $\left(664 \mathrm{~m}^{2} \cdot \mathrm{g}^{-1}\right)>(0.36 / 1)$ 


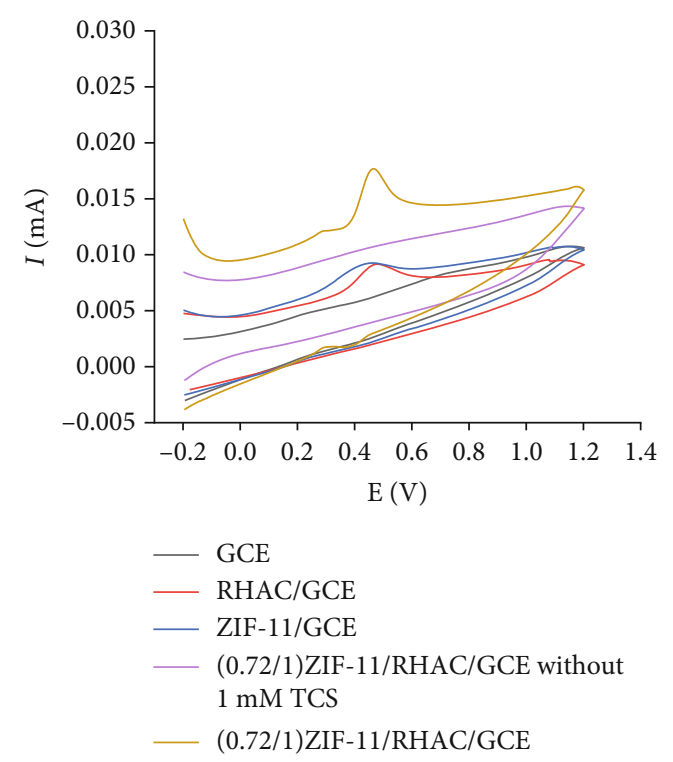

(a)

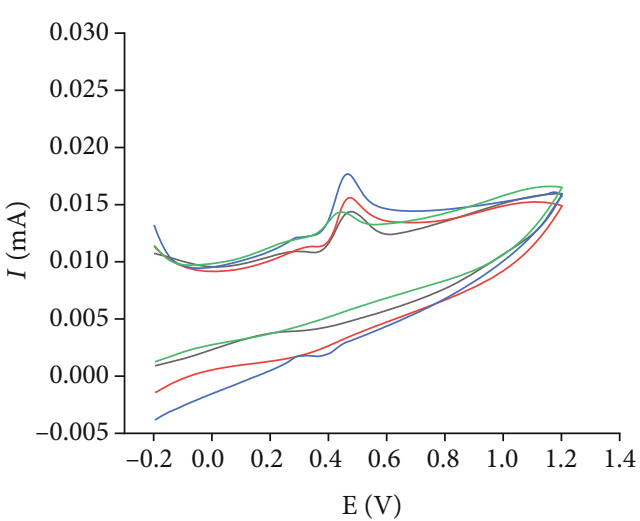

- $(0.36 / 1)$ ZIF-11/RHAC/GCE

- (0.48/1)ZIF-11/RHAC/GCE

- $(0.72 / 1)$ ZIF-11/RHAC/GCE

— (1.03/1)ZIF-11/RHAC/GCE

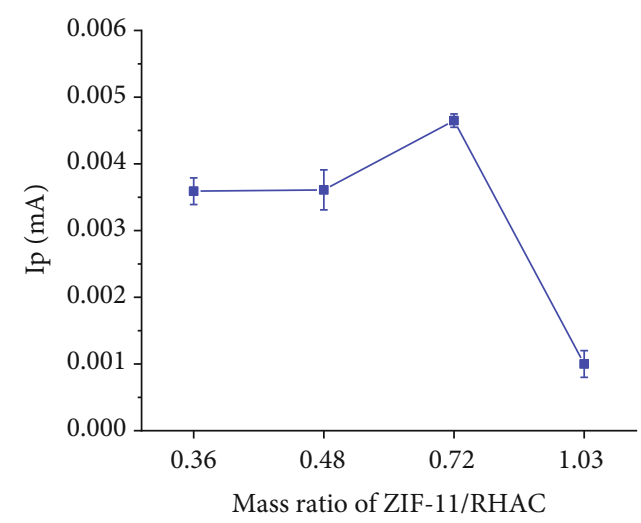

(c)

Figure 7: (a) Cyclic voltammograms of $1 \mathrm{mM}$ TCS in $0.1 \mathrm{M}$ BRS pH 8.0 on a bare glassy carbon electrode (bare GCE), ZIF-11/GCE, RHAC/GCE, and (0.72/1) ZIF-11/RHAC/GCE; (b) cyclic voltammograms of $1 \mathrm{mM}$ TCS on the different ZIF-11/RHAC/GCE; and (c) peak current $I_{\mathrm{p}}$ vs. mass ratio of ZIF-11/RHAC (four scans for each CV measurement).

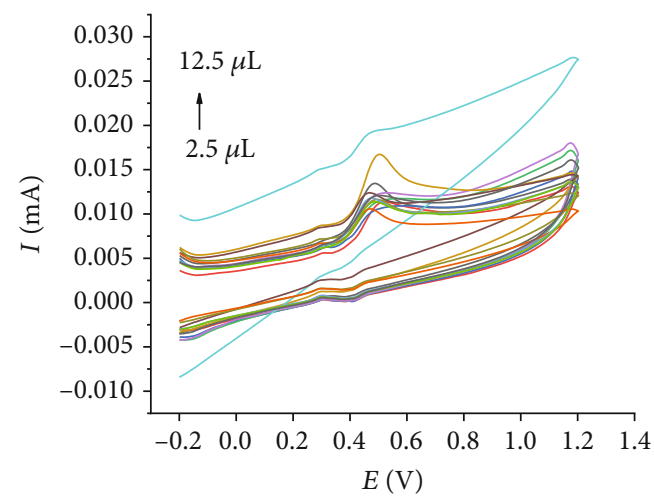

(a)

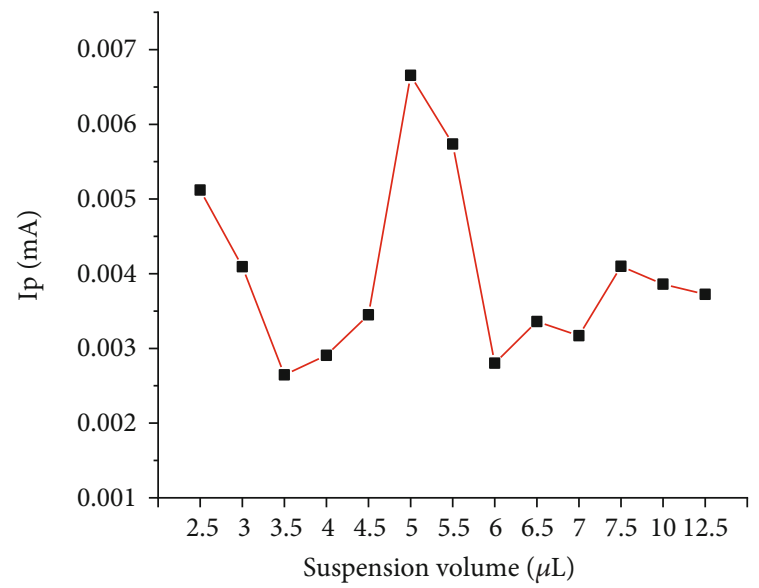

(b)

Figure 8: Cyclic voltammograms (CVs) of $1 \mathrm{mM}$ TCS in $0.1 \mathrm{M} \mathrm{BRB}$ pH 8 in potential range of -0.2 to $1.2 \mathrm{~V}$ at electrode modified with different amount of $(0.72 / 1)$ ZIF-11/RHAC. 


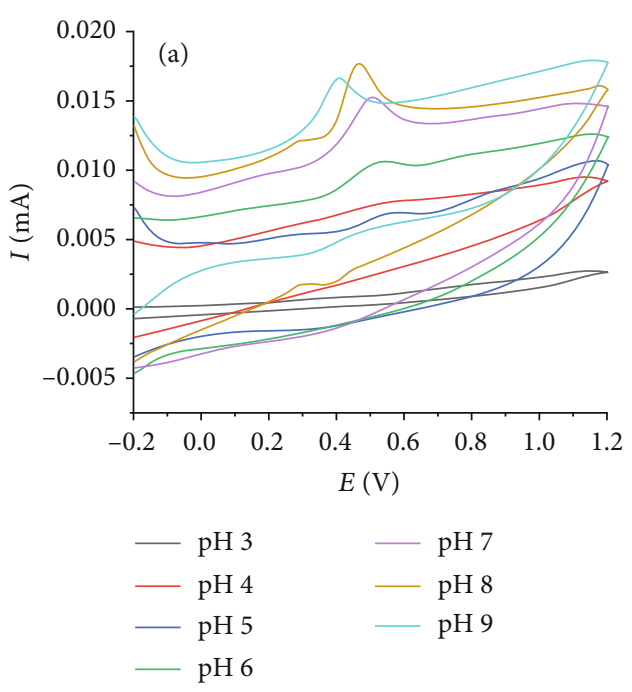

(a)

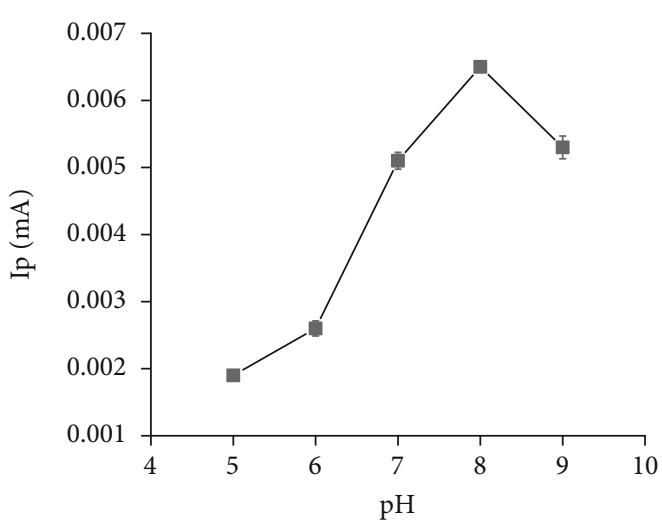

(b)

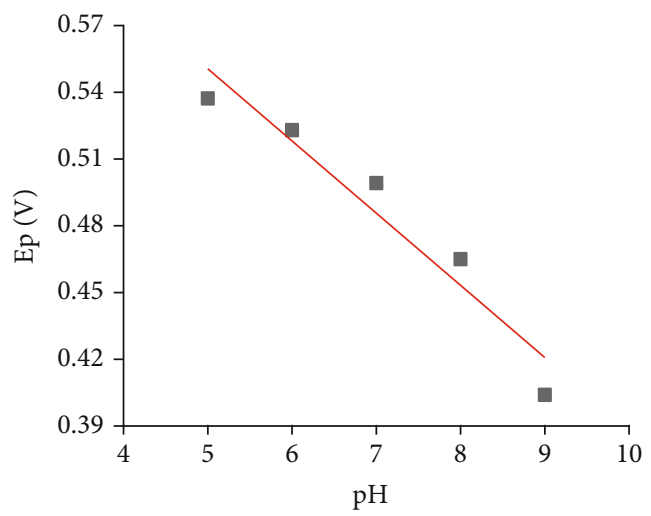

(c)

Figure 9: (a) Cyclic voltammograms of $0.1 \mathrm{mM}$ TCS in 0.1 BRS buffer with pH range of 3-9; (b) peak current versus pH; (c) the linear plot of peak potential versus $\mathrm{pH}$.

ZIF-11/RHAC $\left(443 \mathrm{~m}^{2} \cdot \mathrm{g}^{-1}\right)$ (Table 1$)$. Generally, the surface area of porous materials is contributed mainly by microporous and mesoporous surface area. The mesoporous surface area accounts for up to $47.7 \%(785 / 1500)$ in RHAC material but only $2.2 \%(23 / 1067)$ in ZIF-11. During the synthesis process, the growth of ZIF-11 crystals might possibly block the mesoporous tunnels of RHAC. Hence, the contribution of mesoporous surface area of RHAC is limited causing the decreasing in surface area of ZIF-11/RHAC composites. The increment of surface area with increasing ZIF-11 amount can be assigned to the contribution of microporous surface area of ZIF-11. The volume of total pores presents the same trend in which the total volume increases with increasing ZIF-11 fraction except for (0.48/1) ZIF$11 /$ RHAC. Further investigation is needed to fully explain this behavior.

The $\mathrm{pH}$ stability of (1.03/1) ZIF-11/RHAC was investigated by comparing XRD pattern of ZIF-11/RHAC sample after it was immersed in aqueous solution with $\mathrm{pH}$ range of 2 to 12 for 12 hours (Figure 4). It was found that the characteristic peak of ZIF-11 could not observed in the sample soaked in solution at $\mathrm{pH} 2$. In solutions with $\mathrm{pH}$ ranging from 4 to 12 , the characteristic peaks for ZIF-11 can be clearly observed, yet with a decrease in intensity at lower $\mathrm{pH}$, indicating that (1.03/1) ZIF-11/RHAC is stable in this $\mathrm{pH}$ range.

In order to study the elemental composition of the composites, elemental analysis was conducted using SEMenergy-dispersive X-ray spectrometry (Figure 5). The EDX mapping shows the merged image of elements (Figure 5(a)) and the uniform presence of $\mathrm{O}, \mathrm{C}$, and $\mathrm{Zn}$ (Figures 5(b)-5(d) ) across the sample with a composition of $20.35,76.73$, and $2.92 \%$ in weight or $16.55,82.91$, and 0.58 in atomic, respectively. This also indicates an even distribution of ZIF-11 and RHAC. Furthermore, no other elements can be detected confirming that the preparation of RHAC has completely removed the metal impurities such as $\mathrm{K}, \mathrm{Si}$, and $\mathrm{Na}$.

The point of zero charge (pzc) is described as the $\mathrm{pH}$ at which the net charge of total particle surface (i.e., absorbent's surface) is equal to zero. In the present work, the pzc value is determined by the $\mathrm{pH}$ drift method (Figure 6). At $\mathrm{pH}$ lower than pzc, more hydrogen ions (protons, $\mathrm{H}^{+}$) would be adsorbed than other cations (adsorbate) generating 


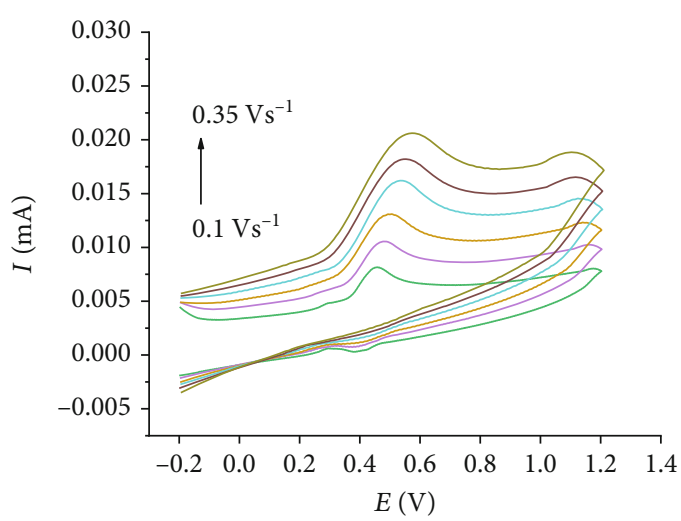

(a)

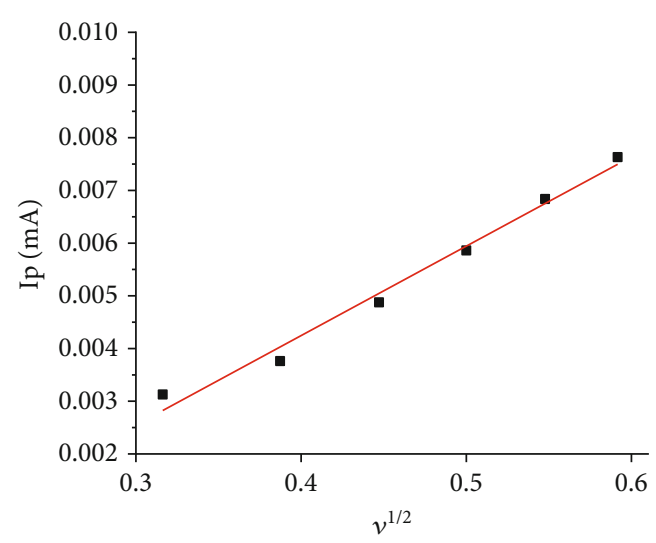

(b)

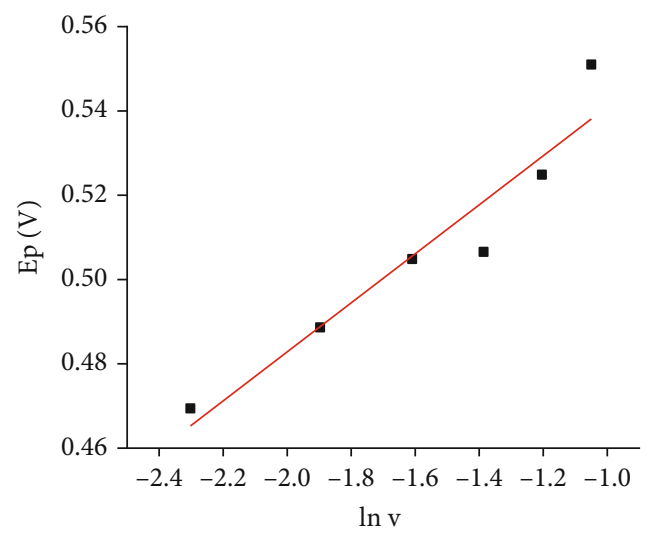

(c)

Figure 10: (a) CV curves of $1 \mathrm{mM}$ TCS in $0.1 \mathrm{M}$ BRS buffer pH 8; (b) the plot of $I_{\mathrm{p}}$ vs. $v$; and (c) the plot of $E_{\mathrm{p}}$ vs. $\ln (v)$.

a positively charged particle surface. On the other hand, as the $\mathrm{pH}$ is higher than pzc, hydroxide anions will be adsorbed leading to negatively charged surface.

\subsection{Electrochemical Determination of Triclosan (TCS) Using (1.5/1) ZIF-11/RHAC-Modified GCE}

\subsubsection{Cyclic Voltametric Behavior of ZIF-11/HRAC-GCE}

(1) The Different Modified Electrodes. The electrochemical behavior of TCS at different electrodes was investigated using cyclic voltammetry (CV). Figure 7 (a) shows the CVs of $1 \mathrm{mM}$ TCS in $0.1 \mathrm{M}$ BRS buffer $\mathrm{pH} 8$ at bare GCE, RHAC, ZIF-11, and (0.72/1) ZIF-11/RHAC/GCE. A blank experiment was done in $0.1 \mathrm{mM}$ BRS buffer $\mathrm{pH} 8$ with the use of $(0.72 / 0.1)$ ZIF-11/RHAC/GCE showing no redox peaks in potential window of $-0.2-1.2 \mathrm{~V}$. It indicates that this material cannot be reduced or oxidized within the chosen working potential range. The redox of TCS cannot be detected at bare GCE- and ZIF-11-modified electrodes. However, at the electrode modified by RHAC or the (0.72/1) ZIF-11/RHAC composite, during the anodic scan from -0.2 to $1.2 \mathrm{~V}$, an oxidation peak at $0.47 \mathrm{~V}$ was observed. On the reverse scan, no reduction peak can be detected, implying that the oxidation of TCS is an irreversible process at the (0.72/1) ZIF11/RHAC/GCE. The CVs of TSC at electrodes modified by<smiles>Oc1cc(Cl)ccc1Oc1ccc(Cl)cc1Cl</smiles>

SCHEME 1: The proposed mechanism of TCS oxidation at $(1.5 / 1)$ ZIF-11/RHAC/GCE.

different ZIF11/RHCA materials are presented at Figure 7(b). All curves present clear oxidation peak of TSC confirming that ZIF-11/RHAC composite is favorable for TSC determination. It is also noticeable that the anodic peak current increased with the increase in the mass ratio of ZIF11 in the composite and peaked at ZIF-11/RHAC ratio of $0.72 / 1$ (Figure $7(\mathrm{c})$ ). The peak current obtained with $(0.72 / 1)$ ZIF-11/RHAC/GCE is the highest despite its surface area being lower than that of (1.03/1) ZIF-11/RHAC/GCE. It can be explained that the electrochemical signals depend not only on the surface area of modified electrode but also on the availability of electrocatalytic sites of the material. Therefore, there is an appropriate ratio of ZIF-11/RHAC for the highest peak current. The sample of $(0.72 / 1)$ ZIF-11/RHAC was used for further experiments.

The enhancement of electrochemical signals at modified electrodes compared to bare GCE might due to the $\pi-\pi$ 


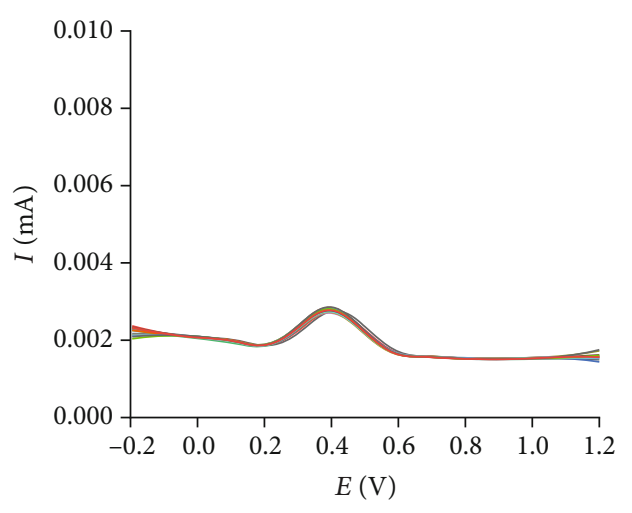

(a)

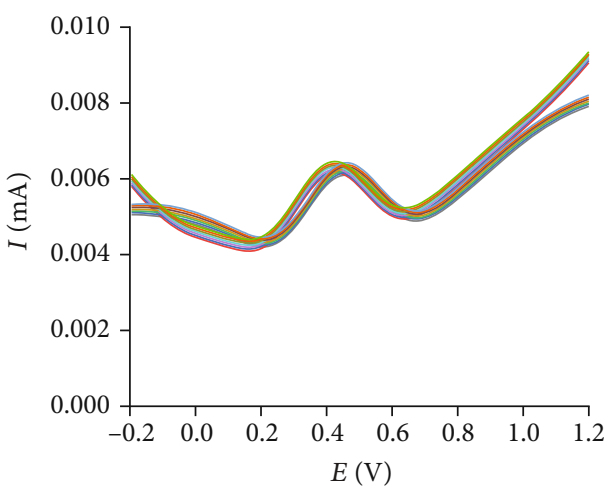

(b)

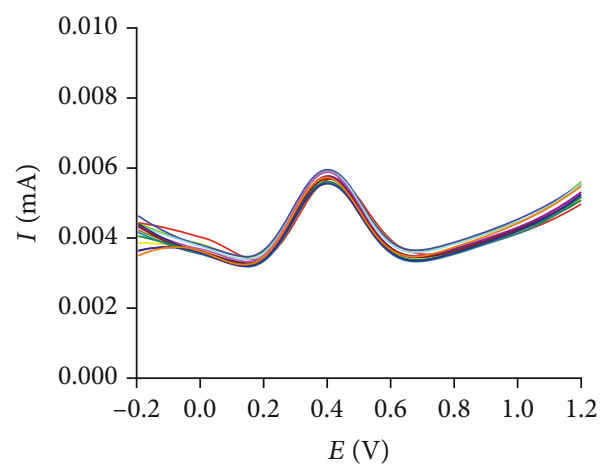

(c)

FIGURE 11: The repeatability of TCS at different concentration: (a) $0.1 \mu \mathrm{M}$, (b) $1 \mu \mathrm{M}$, and (c) $2 \mu \mathrm{M}(0.1 \mathrm{M}$ BRS buffer pH 8).

stacking structure, hydrophobic surface, porous structure nature of RHAC, and high specific area of the ZIF11/RHAC, which allow an effective adsorption of TCS with aromatic rings. Therefore, this composite is a promising candidate for the preconcentration and determination of TCS.

(2) Effect of ZIF-11/RHAC Amount and pH. The effects of $(0.72 / 1)$ ZIF-11/RHAC suspension volume (in the range of $2.5-12.5 \mu \mathrm{L}\left(1 \mathrm{mg} \cdot \mathrm{mL}^{-1}\right)$ on GCE were also investigated (Figure 8(a)). It was found that the magnitude of $I_{p}$ for TCS increases with the increase in suspension volume and peaks at $5 \mu \mathrm{L}$ of (1.5/1) ZIF-11/RHAC suspension. This can be attributed to the enhancement in electrode surface porosity and surface area as well as adsorptive sites, leading to higher accumulation efficiency to TCS. However, the intensity of peak current tends to decrease for suspension volume greater than $5 \mu \mathrm{L}$. It is possible that the larger film thickness of (0.72/1) ZIF-11/RHAC/GCE caused significant resistance against electron transfer in TCS. Considering the oxidation signal and the time for electrode preparation, $5 \mu \mathrm{L}$ of $(0.72 / 1)$ ZIF-11/RHAC suspension was used to modify the GCE surface for further experiments.

Figure 9 presents the influence of $\mathrm{pH}$ of buffer solution on electrochemical signals. When the $\mathrm{pH}$ increases from 5.0 to 8.0 , the anodic current increases. Nevertheless, when the $\mathrm{pH}$ is beyond 8.0 , the peak current conversely decreases (Figure $9(\mathrm{~b})$ ). The $\mathrm{pH}$ of buffer solution decides the exis- tence of different form of TCS which has a $\mathrm{pK}_{\mathrm{a}}$ value of 7.8 [29]. When the $\mathrm{pH}$ is less than $\mathrm{pK}_{\mathrm{a}}$, TCS exists in molecular form while the ionic form is more predominant in alkaline solution. Furthermore, the point of zero charge for (0.72/1) ZIF-11/RHAC is found to be 6.4 (Figure 6) which means that at high $\mathrm{pH}$ value $(>6.4)$, the electrode surface is negatively charged. Therefore, in alkaline buffer solution $(\mathrm{pH}>8)$, the repulsion of anion form of TCS and negatively charged electrode surface is significant, causing the reduction of peak current.

The linear relationship of $E_{\mathrm{p}}$ vs. $\mathrm{pH}$ is illustrated by linear regression equation as follows (Figure 9(c)):

$$
E_{\mathrm{p}}=(0.71 \pm 0.04)+(-0.0324 \pm 0.005) \mathrm{pH} r=0.964
$$

The slope of 0.0324 is approximately half of the theoretical value of 0.0592 in the Nernst equation. It means that the protons are twice as much as electrons transferred in this oxidation process. This result is different from the result of Pemberton and Hart [30] in which the TCS oxidation involves the equal one number of electron and proton.

(3) Effect of Scan Rate. The effect of scan rate $(v)$ on electrochemical signals of TCS were also investigated. As can be seen from the figure the oxidation peak potential $\left(E_{\mathrm{p}}\right)$ of TCS shifts to more positive potentials with increasing scan rate suggesting that the TCS oxidation is an irreversible process (Figure 10(a)). In addition, as $v$ increases 
from 0.1 to $0.35 \mathrm{~V} \mathrm{~s}^{-1}$, the anodic peak current $\left(I_{\mathrm{p}}\right)$ is linearly proportional with the square root of $v$ $\left(I_{\mathrm{p}, \mathrm{TCS}}=(-0.0025 \pm 0.0003)+(0.0168 \pm 0.0005) v^{1 / 2}, r=\right.$ $0.996)$, also indicating that the TCS oxidation is a diffusion controlled process [31]. For the irreversible electrochemical process, the relationship between the potential and scan rate could be presented by Laviron equation [32]: $\quad E_{\mathrm{p}}=E^{0}-(\mathrm{RT} / \alpha \mathrm{nF}) \ln \left(\mathrm{RTk}_{\mathrm{s}} / \alpha \mathrm{nF}\right)+(\mathrm{RT} / \alpha \mathrm{nF}) \ln \nu$, where $a$ is the electron transfer coefficient, $n$ is the number of transfer electron, $k_{\mathrm{s}}$ is the standard heterogeneous rate constant, $R=8.314 \mathrm{~J} / \mathrm{mol} \cdot \mathrm{K}, F=96500 \mathrm{C} \cdot \mathrm{mol}^{-1}$ at $T$ $=298 \mathrm{~K}$.

The linear relationship between $E_{\mathrm{p}}$ and natural logarithm of $v$ in the oxidation of TCS is as follows (Figure 10(c)):

$$
E_{\mathrm{p}}, \mathrm{TCS}=(0.60 \pm 0.01)+(0.058 \pm 0.009) \ln (v) \quad r=0.956
$$

The value of $\alpha \bullet n$ can be obtained from the slope of $E_{\mathrm{p}}$ vs. $\ln v$ plot. In this case, the slope was $0.058 \mathrm{mV}$. Therefore, the value of $\alpha \bullet n$ is 0.46 . The value of $\alpha$ is considered to be 0.5 in totally irreversible electrode process [10], making the number of electron $(n)$ transferred in the electrooxidation of TCS being 0.96 or $n$ is confirmed as 1 . Therefore, the number of protons is 2 . The value of $n$ is published differently by author which is equal to 1 for authors $[11,31,33$ ] and 2 for Li et al. [34]. The oxidation reaction of TCS on (1.5/1) ZIF-11/RHAC/GCE with a one-electron transfer and two-proton process is proposed as Scheme 1.

3.2.2. Analytical Performance: Repeatability, Selectivity, and Limit of Detection. The repeatability of the TCS determination was determined at different concentrations of $0.1 \mu \mathrm{M}$, $1 \mu \mathrm{M}$, and $2 \mu \mathrm{M}$ in $0.1 \mathrm{M}$ BRS buffer $\mathrm{pH} 8$ by DPV using the (1.5/1) ZIF-11/RHAC/GCE in fourteen successive cycles (Figure 11). The relative standard deviation (R.S.D.) for $n=14$ is $3.9 \%$ for $0.1 \mu \mathrm{M}$ TCS, $3.5 \%$ for $1 \mu \mathrm{M}$ TCS, and $2.0 \%$ for $2 \mu \mathrm{M}$ TCS which are less than those of $1 / 2 . \mathrm{RSD}_{\mathrm{H}}$ $\left(\mathrm{RSD}_{\mathrm{H}}=2^{(1-0.5 \log \mathrm{C})}\right)$ suggesting that the proposed DPV method provides an excellent repeatability.

A qualified electrode should have better selectivity of TCS over other potential interferences in the determination of real samples. Therefore, the influence of certain organic substances and inorganic ions was studied in the present work. At designated amount of chosen interferents, the peak current deviation of TCS is within $\pm 5 \%$ (Table 3). $\mathrm{Al}\left(\mathrm{NO}_{3}\right)_{3}$ has the least impact on TCS determination when at 160-fold excess and other inorganic salts $\left(\mathrm{Na}_{2} \mathrm{SO}_{4}, \mathrm{CaCl}_{2}, \mathrm{Cu}\left(\mathrm{NO}_{3}\right)_{2}\right.$, $\mathrm{ZnCl}_{2}$ ) exhibit interference as at 16 -fold excess; the difference in peak current is still within the limit of tolerance. Some organic compounds cause the impact as 8-16-fold excess as shown in Table 2. This result indicated that the prepared electrode in the present study had a satisfactory selectivity to TCS.

Figure 12(a) presents DPV curves of solution containing increasing TCS concentration from $0.1 \mu \mathrm{M}$ to $8.0 \mu \mathrm{M}$ and
TABLE 3: Effect of several interferents on the peak current of $0.1 \mu \mathrm{M}$ TCS in $0.1 \mathrm{M}$ BRS buffer (pH 8) at the (0.72/1) ZIF-11/RHAC/GCE.

\begin{tabular}{|c|c|c|c|}
\hline Interferent & $\begin{array}{c}\text { Interferent : TCS } \\
(\mathrm{M} / \mathrm{M})\end{array}$ & $I_{\mathrm{p}}(\mu \mathrm{A})$ & $\operatorname{Re}(\%)$ \\
\hline \multirow{2}{*}{$\mathrm{KHCO}_{3}$} & $0: 1$ & 1.20 & 0.00 \\
\hline & $32: 1$ & 1.15 & -4.49 \\
\hline \multirow{2}{*}{$\mathrm{Na}_{2} \mathrm{SO}_{4}$} & $0: 1$ & 1.16 & 0.00 \\
\hline & $16: 1$ & 1.10 & -4.81 \\
\hline \multirow{2}{*}{$\mathrm{CaCl}_{2}$} & $0: 1$ & 1.19 & 0.00 \\
\hline & $16: 1$ & 1.12 & -4.24 \\
\hline \multirow{2}{*}{$\mathrm{Fe}\left(\mathrm{NO}_{3}\right)_{3}$} & $0: 1$ & 1.22 & 0.00 \\
\hline & $32: 1$ & 1.17 & -4.45 \\
\hline \multirow{2}{*}{$\mathrm{Cu}\left(\mathrm{NO}_{3}\right)_{2}$} & $0: 1$ & 1.11 & 0.00 \\
\hline & $16: 1$ & 1.03 & -4.40 \\
\hline \multirow{2}{*}{$\mathrm{MgCl}_{2}$} & $0: 1$ & 1.20 & 0.00 \\
\hline & $16: 1$ & 1.14 & -4.91 \\
\hline \multirow{2}{*}{$\mathrm{ZnCl}_{2}$} & $0: 1$ & 1.20 & 0.00 \\
\hline & $16: 1$ & 1.14 & -5.05 \\
\hline \multirow{2}{*}{$\mathrm{Al}\left(\mathrm{NO}_{3}\right)_{3}$} & $0: 1$ & 1.20 & 0.00 \\
\hline & $160: 1$ & 1.12 & -4.85 \\
\hline \multirow{2}{*}{$\begin{array}{l}\text { Sodium } \\
\text { benzenesulphinate }\end{array}$} & $0: 1$ & 1.10 & 0.00 \\
\hline & $24: 1$ & 1.06 & -3.64 \\
\hline \multirow{2}{*}{ Methyl salicylate } & $0: 1$ & 1.06 & 0.00 \\
\hline & $10: 1$ & 1.10 & 3.77 \\
\hline \multirow{2}{*}{ Cinnamaldehyde } & $0: 1$ & 1.11 & 0.00 \\
\hline & $8: 1$ & 1.06 & -4.50 \\
\hline \multirow{2}{*}{ m-Trihydroxybenzene } & $0: 1$ & 1.09 & 0.00 \\
\hline & $16: 1$ & 1.05 & -3.67 \\
\hline \multirow{2}{*}{ p-Nitro phenol } & $0: 1$ & 1.22 & 0.00 \\
\hline & $12: 1$ & 1.18 & -3.28 \\
\hline
\end{tabular}

the resulted calibration curve. The linear equation was found to be $I_{\mathrm{p},}(\mathrm{mA})=(0.00103 \pm 0.00002)+(0.00132 \pm 0.00006)$ $C_{\mathrm{M}}(\mu \mathrm{M})(r=0.999) \quad$ (Figure 12(b)). The detection limit $(3 \mathrm{~s} / b)$ of this method was $0.076 \mu \mathrm{M}$, where $s$ is the blank standard deviation and $b$ is the slope of the calibration curve in the linear concentration range. Table 4 presents the comparison of LOD of the proposed method with other electrochemical methods. It was found that the present LOD is comparable to previous publications.

3.2.3. Real Sample Analysis. Quantification of TCS in cosmetic samples was conducted by the proposed DPV method (Table 5). The samples (01 lipstick, 01 skin cream, and 03 cleansers) were purchased at the local area. The HPLC analysis of the same samples was also carried for comparison. The recovery was in the expectable range from $96.0 \%$ to $106.3 \%$, indicating that the proposed method might be sufficient for practical applications. The paired samples $t$-test with $\alpha=0.05$ indicates that both methods were statistically not different $(p$ (two tailed $)=0.388>0.05 ; t(7)=0.921)$ suggesting the accuracy and feasibility of the present electrode in the detection of TCS in real samples. 


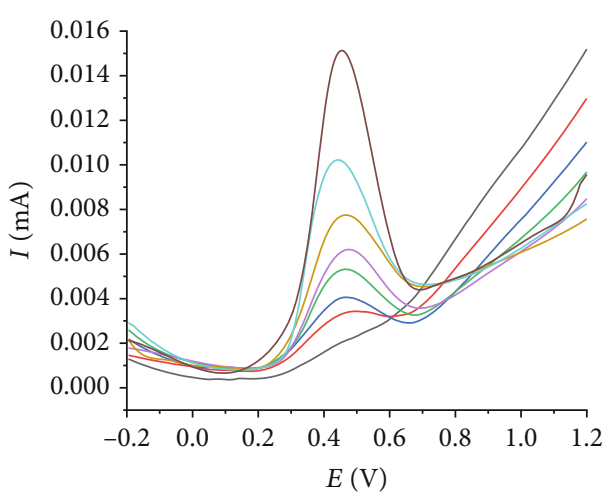

(a)

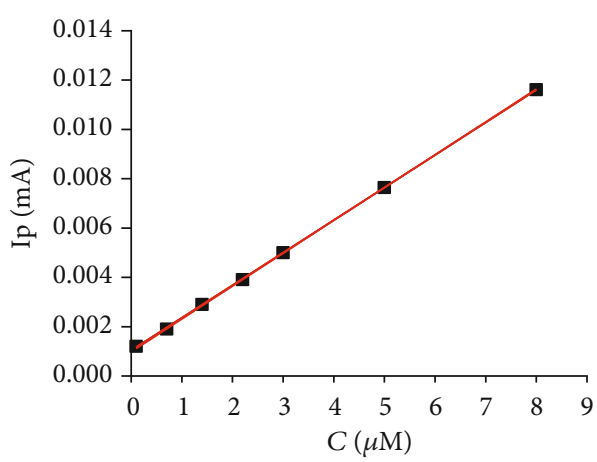

(b)

Figure 12: (a) DPV curves at various concentrations and (b) the plot of $I_{\mathrm{p}}$ vs. TCS concentration in the range from $0.1 \mu \mathrm{M}$ to $8.0 \mu \mathrm{M}$ (pulse attitude: $0.07 \mathrm{~V}$, scan rate: $0.0625 \mathrm{Vs}^{-1}$, accumulation potential: $-0.8 \mathrm{~V}$, accumulation time: $25 \mathrm{~s}$, in $0.1 \mathrm{M}$ RBS buffer $\mathrm{pH} 8$ ).

TABLE 4: Comparison of LOD of the proposed DPV method with previous publications.

\begin{tabular}{|c|c|c|c|c|}
\hline Electrode modifier & Method & Linear range $(\mu \mathrm{M})$ & LOD $(\mu \mathrm{M})$ & References \\
\hline An ordered mesoporous carbon & SWV & $2.7 \times 10^{-3}-0.14$ & $0.82 \times 10^{-3}$ & {$[8]$} \\
\hline Carbon nanodots/chitosan & LSV & $10^{-2}-10^{3}$ & $9.2 \times 10^{-3}$ & {$[11]$} \\
\hline $\begin{array}{l}\text { Poly(diallyldimethylammonium chloride)-functionalized graphene/palladium } \\
\text { nanoparticles }\end{array}$ & DPV & $9 \times 10^{-3}-20$ & $3.5 \times 10^{-3}$ & [9] \\
\hline Multiwall carbon nanotube film & & $0.17-6.044$ & $57 \times 10^{-3}$ & {$[31]$} \\
\hline$\beta$-Cyclodextrin functionalized graphene nano platelets & & $2-100$ & 0.6 & {$[10]$} \\
\hline Tosyl-functionalized carbon nanoparticles & $\mathrm{CV}$ & $10-100$ & 10 & {$[35]$} \\
\hline ZIF-11/activated carbon derived from rice husk & DPV & $0.1-8$ & 0.076 & $\begin{array}{c}\text { The present } \\
\text { work }\end{array}$ \\
\hline
\end{tabular}

TABLE 5: Comparison of TCS concentration in cometic samples by DPV and high-performance liquid chromatography.

\begin{tabular}{|c|c|c|c|c|c|c|}
\hline \multirow{2}{*}{ Sample } & \multicolumn{3}{|c|}{ DPV } & \multicolumn{3}{|c|}{ HPLC } \\
\hline & Original content $(\mu \mathrm{M})$ & Spiked $(\mu \mathrm{M})$ & Found $(\mu \mathrm{M})$ & $\operatorname{Rev}(\%)$ & Original content $(\mu \mathrm{M})$ & Found $(\mu \mathrm{M})$ \\
\hline No. 1 & Not found & 2 & $1.94 \pm 0.06(\mathrm{a})$ & 96.8 & Not found & $1.949 \pm 0.001$ \\
\hline No. 2 & Not found & 2 & $2.13 \pm 0.04$ & 106.3 & Not found & $2.061 \pm 0.024$ \\
\hline No. 3 & Not found & 2 & $1.98 \pm 0.10$ & 98.9 & Not found & $1.919 \pm 0.014$ \\
\hline No. 4 & Not found & 2 & $1.96 \pm 0.08$ & 97.9 & Not found & $2.020 \pm 0.002$ \\
\hline No. 5 & $1.10 \pm 0.05$ & 2 & $3.12 \pm 0.09$ & 101.0 & $1.028 \pm 0.018$ & $3.967 \pm 0.042$ \\
\hline No. 6 & $1.81 \pm 0.03$ & 2 & $3.80 \pm 0.10$ & 99.5 & $1.950 \pm 0.008$ & $3.892 \pm 0.007$ \\
\hline No. 7 & $3.57 \pm 0.06$ & 2 & $5.49 \pm 0.12$ & 96.0 & $3.381 \pm 0.070$ & $5.419 \pm 0.006$ \\
\hline No. 8 & $0.58 \pm 0.01$ & 2 & $2.63 \pm 0.06$ & 102.5 & $0.436 \pm 0.011$ & $2.401 \pm 0.030$ \\
\hline
\end{tabular}

(a) Mean of three determinations \pm S.D.

\section{Conclusion}

The composite of ZIF-11 and activated carbon derived from rice husks has been synthesized by ultrasonication-assisted method. The ZIF-11/RHAC composites possessed high surface area with homogeneously mixing of ZIF-11 and RHAC. The ZIF-11/RHAC composite showed highly efficient catalytic activity towards the electrooxidation of TCS by promoting the electron kinetics. The proposed method exhibited great selectivity and sensitivity on TCS detection with a level of detection of $0.076 \mu \mathrm{M}$, providing a potential tool for TCS detection in environmental samples.

\section{Data Availability}

The data used to support the findings of this study are available from the corresponding author upon request. 


\section{Conflicts of Interest}

The authors declare that they have no conflicts of interest.

\section{Acknowledgments}

The author (Nguyen Dinh Luyen) would like to thank the Hue University for funding this project with code number DHH 2020-03-146.

\section{References}

[1] J.-L. Fang, R. L. Stingley, F. A. Beland, W. Harrouk, D. L. Lumpkins, and P. Howard, "Occurrence, efficacy, metabolism, and toxicity of triclosan," Journal of Environmental Science and Health, Part C, vol. 28, no. 3, pp. 147-171, 2010.

[2] S. Chu and C. D. Metcalfe, "Simultaneous determination of triclocarban and triclosan in municipal biosolids by liquid chromatography tandem mass spectrometry," Journal of Chromatography. A, vol. 1164, no. 1-2, pp. 212-218, 2007.

[3] D. R. Orvos, D. J. Versteeg, J. Inauen, M. Capdevielle, A. Rothenstein, and V. Cunningham, "Aquatic toxicity of triclosan," Environmental Toxicology and Chemistry: An International Journal, vol. 21, no. 7, pp. 1338-1349, 2002.

[4] J.-H. Guo, X.-H. Li, X.-L. Cao, Y. Li, X.-Z. Wang, and X.B. $\mathrm{Xu}$, "Determination of triclosan, triclocarban and methyltriclosan in aqueous samples by dispersive liquid-liquid microextraction combined with rapid liquid chromatography," Journal of Chromatography. A, vol. 1216, no. 15, pp. 3038-3043, 2009.

[5] H. Lu, H. Ma, and G. Tao, "Spectrophotometric determination of triclosan in personal care products," Spectrochimica Acta Part A: Molecular and Biomolecular Spectroscopy, vol. 73, no. 5, pp. 854-857, 2009.

[6] M. Allmyr, M. S. McLachlan, G. Sandborgh-Englund, and M. Adolfsson-Erici, "Determination of triclosan as its pentafluorobenzoyl ester in human plasma and milk using electron capture negative ionization mass spectrometry," Analytical Chemistry, vol. 78, no. 18, pp. 6542-6546, 2006.

[7] O. Akyıldırım, "A sensitive voltammetric sensor based on silver nanoparticles/carbon nitride nanotubes@ graphene quantum dots/a novel organic liquid: determination of triclosan in wastewater," Bulletin of Materials Science, vol. 43, pp. 1-8, 2020.

[8] M. Regiart, J. L. Magallanes, D. Barrera et al., "An ordered mesoporous carbon modified electrochemical sensor for solid-phase microextraction and determination of triclosan in environmental samples," Sensors and Actuators B: Chemical, vol. 232, pp. 765-772, 2016.

[9] T. Wu, T. Li, Z. Liu, Y. Guo, and C. Dong, "Electrochemical sensor for sensitive detection of triclosan based on graphene/palladium nanoparticles hybrids," Talanta, vol. 164, pp. 556562, 2017.

[10] B. Li, Z. Qiu, Q. Wan, Y. Liu, and N. Yang, “ $\beta$-cyclodextrin functionalized graphene nano platelets for electrochemical determination of triclosan," physica status solidi (a), vol. 211, pp. 2773-2777, 2014.

[11] H. Dai, G. Xu, L. Gong et al., "Electrochemical detection of triclosan at a glassy carbon electrode modifies with carbon nanodots and chitosan," Electrochimica Acta, vol. 80, pp. 362-367, 2012.
[12] K. S. Park, Z. Ni, A. P. Côté et al., "Exceptional chemical and thermal stability of zeolitic imidazolate frameworks," Proceedings of the National Academy of Sciences, vol. 103, no. 27, pp. 10186-10191, 2006.

[13] B. Assfour, S. Leoni, and G. Seifert, "Hydrogen adsorption sites in zeolite imidazolate frameworks ZIF-8 and ZIF-11," Journal of Physical Chemistry C, vol. 114, pp. 13381-13384, 2010.

[14] E. M. Forman, A. Baniani, L. Fan et al., "Relationship between ethane and ethylene diffusion inside ZIF-11 crystals confined in polymers to form mixed-matrix membranes," Journal of membrane science, vol. 593, p. 117440, 2020.

[15] G. P. Pandey, A. C. Rastogi, and C. R. Westgate, “All-solidstate supercapacitors with poly (3, 4-ethylenedioxythiophene)-coated carbon fiber paper electrodes and ionic liquid gel polymer electrolyte," Journal of Power Sources, vol. 245, pp. 857-865, 2014.

[16] J. Jiang, L. Zhang, X. Wang et al., "Highly ordered macroporous woody biochar with ultra-high carbon content as supercapacitor electrodes," Electrochimica Acta, vol. 113, pp. 481-489, 2013.

[17] A. Salanti, L. Zoia, M. Orlandi, F. Zanini, and G. Elegir, "Structural characterization and antioxidant activity evaluation of lignins from rice husk," Journal of Agricultural and Food Chemistry, vol. 58, no. 18, pp. 10049-10055, 2010.

[18] E. Y. L. Teo, L. Muniandy, E.-P. Ng et al., "High surface area activated carbon from rice husk as a high performance supercapacitor electrode," Electrochimica Acta, vol. 192, pp. 110119,2016

[19] L. Muniandy, F. Adam, A. R. Mohamed, and E.-P. Ng, "The synthesis and characterization of high purity mixed microporous/mesoporous activated carbon from rice husk using chemical activation with $\mathrm{NaOH}$ and $\mathrm{KOH}$," Microporous and Mesoporous Materials, vol. 197, pp. 316-323, 2014.

[20] B. R. Pimentel, M. L. Jue, E.-K. Zhou et al., "Sorption and transport of vapors in ZIF-11: adsorption, diffusion, and linker flexibility," Journal of Physical Chemistry C, vol. 123, pp. 12862-12870, 2019.

[21] Y. Jiao, D. Han, Y. Lu et al., "Characterization of pine-sawdust pyrolytic char activated by phosphoric acid through microwave irradiation and adsorption property toward CDNB in batch mode," Desalination and Water Treatment, vol. 77, pp. 247-255, 2017.

[22] K. S. W. Sing, H. D. Everett, W. A. R. Haul et al., "Reporting physisorption data for gas/solid systems with special reference to the determination of surface area and porosity (Recommendations 1984)," Pure and applied chemistry, vol. 57, no. 4, pp. 603-619, 1985.

[23] J. Rouquerol, D. Avnir, C. W. Fairbridge et al., "Recommendations for the characterization of porous solids (Technical Report)," Pure and Applied Chemistry, vol. 66, no. 8, pp. 1739-1758, 1994.

[24] D. W. Breck, Zeolite Molecular Sieves, vol. 634, Wiley, New York, 1974.

[25] A. Noguera-Díaz, J. Villarroel-Rocha, V. P. Ting, N. Bimbo, K. Sapag, and T. J. Mays, "Flexible ZIFs: probing guestinduced flexibility with CO2, N2 and Ar adsorption," Journal of Chemical Technology and Biotechnology, vol. 94, pp. 37873792, 2019.

[26] M. S. Boroglu and A. B. Yumru, "Gas separation performance of 6FDA-DAM-ZIF-11 mixed-matrix membranes for $\mathrm{H}_{2} / \mathrm{CH}_{4}$ and $\mathrm{CO}_{2} / \mathrm{CH}_{4}$ separation," Separation and Purification Technology, vol. 173, pp. 269-279, 2017. 
[27] J. M. Lucero, T. J. Self, and M. A. Carreon, "Synthesis of ZIF-11 crystals by microwave heating," New Journal of Chemistry, vol. 44, pp. 3562-3565, 2020.

[28] E. Menya, P. W. Olupot, H. Storz, M. Lubwama, and Y. Kiros, "Production and performance of activated carbon from rice husks for removal of natural organic matter from water: a review," Chemical Engineering Research and Design, vol. 129, pp. 271-296, 2018.

[29] J. Greenman and D. G. A. Nelson, "Hydrolysis of triclosan monophosphate by dental plaque and selected species of oral micro-organisms," Journal of Dental Research, vol. 75, pp. 1578-1584, 1996.

[30] R. M. Pemberton and J. P. Hart, "Electrochemical behaviour of triclosan at a screen-printed carbon electrode and its voltammetric determination in toothpaste and mouthrinse products," Analytica Chimica Acta, vol. 390, pp. 107-115, 1999.

[31] J. Yang, P. Wang, X. Zhang, and K. Wu, "Electrochemical sensor for rapid detection of triclosan using a multiwall carbon nanotube film," Journal of Agricultural and Food Chemistry, vol. 57, pp. 9403-9407, 2009.

[32] E. Laviron, "General expression of the linear potential sweep voltammogram in the case of diffusionless electrochemical systems," Journal of Electroanalytical Chemistry and Interfacial Electrochemistry, vol. 101, no. 1, pp. 19-28, 1979.

[33] J. Zheng, M. Zhang, Y. Ling et al., "Fabrication of one dimensional CNTs/ $/ \mathrm{Fe}_{3} \mathrm{O}_{4} @ \mathrm{PPy} / \mathrm{Pd}$ magnetic composites for the accumulation and electrochemical detection of triclosan," Journal of Electroanalytical Chemistry, vol. 818, pp. 97-105, 2018.

[34] H. Li, Z. Deng, Q. Tian et al., "Application of carbon nanotubes and zwitterionic surfactant-modified acetylene black electrode for the determination of triclosan in household commodities," International Journal of Environmental Analytical Chemistry, pp. 1-14, 2020.

[35] L. Vidal, A. Chisvert, A. Canals et al., "Chemically surfacemodified carbon nanoparticle carrier for phenolic pollutants: extraction and electrochemical determination of benzophenone-3 and triclosan," Analytica Chimica Acta, vol. 616, no. 1, pp. 28-35, 2008. 